\title{
Updates in Internal Medicine: a symposium organised by the Trainees and Members' Committee
}

\author{
Held on 23 October 2009 at the Royal College of Physicians of Edinburgh \\ V Tallentire \\ Fellow in Medical Education, Medical Teaching Organisation, University of Edinburgh, \\ Edinburgh, UK
}

DECLARATION OF INTERESTS No conflict of interests declared.

\begin{abstract}
Correspondence to V Tallentire, Medical Teaching Organisation, University of Edinburgh, Chancellor's Building, 49 Little France Crescent, Edinburgh EHI6 4SB, UK
\end{abstract}

tel. +44 (0) I3I 2426368

e-mail Vicky.Tallentire@ed.ac.uk
The Collegiate Members' symposium, now in its 39th year, attracted a large audience, provided informative and varied lectures and stimulated impassioned debate.The symposium, titled 'Updates in Internal Medicine', focused on clinically relevant topics that are applicable to medical students, doctors and allied health professionals of all levels. It also provided a unique opportunity for Associate and Collegiate Members to present their own clinical lessons, both as brief oral presentations and in poster format.

\section{HOW TO DEAL WITH...}

The first session incorporated presentations by three charismatic speakers dealing with common clinical 'headaches'. Dr Raeburn Forbes (Craigavon Area Hospital, Portadown) took the literal meaning of 'the headache patient', reminding the audience that the key to headache diagnosis is good history-taking, and included useful tips such as the recommendation that atraumatic $22 \mathrm{G}$ spinal needles should be used routinely to reduce post-lumbar puncture headache.

Professor Hugh Pennington (Aberdeen University) provided a thought-provoking presentation on 'superbugs', focusing on the history of penicillin-resistant Staphylococcus and the endemic problem of Clostridium difficile.' He gave a fascinating insight into the public enquiry at Maidstone and Tunbridge Wells NHS Trust, ${ }^{2}$ highlighting that before the outbreak of $C$. difficile infection the Trust only monitored the methicillin-resistant Staphylococcus aureus (MRSA) rate, as there was a national performance target in relation to MRSA but not $C$. difficile. He cautioned against the narrowed focus of any infection-control policies, reiterating one of the key lessons of that devastating outbreak.

Dr Sean Fenwick (City Hospitals, Sunderland), back by popular demand following his memorable contribution in 2008, delivered an excellent, clinically based presentation on acute kidney injury focusing on 'the reasons to wake him up at 3am', such as hyperkalaemia and fluid overload requiring renal replacement therapy. He used interactive case studies on common problems such as obstructive renal failure to remind us that most interesting rarities can usually wait until the morning and should not be the mainstay of a general physician's renal knowledge!

\section{RADIOLOGY: MORE THAN X-RAY}

The second session of the morning provided ample opportunity for high-resolution images of newer imaging modalities. Dr Maggie Brooks (Aberdeen Royal Infirmary) showed the first ever radiological image, from 1895, and briefly explained the concepts of gamma ray production and annihilation reactions in her introduction to positron emission tomography (PET). No longer simply an oncological diagnostic tool, PET has been used in the diagnosis of inflammatory conditions such as tuberculosis and even large vessel vasculitis. Dr Anne Scott (Stirling Royal Infirmary) spoke about the rise of cardiac magnetic resonance imaging (MRI) and provided images from conditions including Fallot's tetralogy, mesothelioma and arrhythmogenic right ventricular dysplasia. She discussed the potential difficulties in differentiating myocarditis from subendocardial infarction on clinical criteria alone and the potential for MRI to help establish a firm diagnosis. Dr Allister Taggart (Musgrave Park Hospital, Belfast) discussed musculoskeletal ultrasound and its varied roles, including diagnosis clarification (for example, differentiating between psoriatic arthritis and gout), the detection of early rheumatoid arthritis, monitoring response to treatment, especially in clinical trials, and direct visualisation of joint injections. Dr Alistair Todd (Raigmore Hospital, Inverness) provided an entertaining and eclectic radiology quiz that included post-mortem computed tomography scans, sword swallowing images and even a tortoise $\mathrm{X}$-ray!

\section{CROOM LECTURE}

Dr Phillip Riches (University of Edinburgh) delivered a fascinating 36th Croom Lecture on his research in osteoporosis associated with neutralising autoantibodies to osteoprotegerin. ${ }^{3} \mathrm{He}$ captivated the audience with his complex scientific theory cleverly applied to a clinical scenario and offered a fascinating glimpse of possible future investigation and therapeutic options (see his review on pages 66-69). 


\section{'CLINICAL LESSONS'}

The standard of the clinical lessons from e-Associates, Associates and Members of the RCPE remains extremely high and the six presenters provided thought-provoking case presentations. The winning Associate member was Dr Indrani Bhattacharya (Victoria Hospital, Kirkcaldy), who spoke about 'a dizzy American' presenting with syncope due to complete heart block secondary to Lyme disease. Dr Caroline Coats (The Heart Hospital, London), the winning Collegiate Member, spoke about a case of collapse in the context of conduction disease and left ventricular hypertrophy, ultimately diagnosed as cardiac sarcoidosis.

\section{RATIONING AND RESOURCES IN THE NHS}

The final session of the day mirrored the success of 2008 , again using a panel discussion to provoke audience and speaker debate. Three clinical cases highlighted the topical resource issues surrounding the provision of intensive care, with the audience voting to 'admit or not admit' to a theoretical intensive care unit. Dr Martin Wilson (Raigmore Hospital, Inverness) discussed the implications of an ageing population in terms of increased demand for critical care beds and argued that physiological age, often the basis for clinical decision-making, is inseparable from chronological age. Dr Bryce Randalls
(Aberdeen) discussed the often overlooked financial and psychological implications of intensive care and the burden of these on society. Professor Ken Paterson (Scottish Medicines Consortium) highlighted the huge discrepancies between the rigorous financial justifications required by the government for new drug licensing compared to the relatively lenient approach to new intensive care developments. He argued persuasively for uniformity in cost-effectiveness analysis across all aspects of healthcare in the context of scientific development and ever-rising public expectation.

\section{TAKE-HOME MESSAGES}

This clinically orientated and thoroughly interactive symposium provided tips on day-to-day practice in terms of clinical examination, investigation using newer modalities and the treatment of acute problems. The lively debate at the end of the day reminded us all of the difficult decisions that we face as healthcare professionals and the occasional conflicting obligations of individual versus public health in the uncomfortable but unavoidable field of resource allocation.

The Trainees and Members' Committee welcomes suggestions for topics or formats for inclusion in the 2010 symposium (please contact a.fairbairn@rcpe.ac.uk).

\section{REFERENCES}

I Pennington TH, editor. When food kills: BSE, E.coli, and disaster science. Oxford: Oxford University Press; 2003.

2 http://www.whittington.nhs.uk/Documents/ltem\%207_6135.5\%20 \%20PAGES\%203-9\%20ONLY\%20HCC\%20investigation\%20 maidstone\%20and\%20tunbridge\%20wells_6I35.pdt

Riches PL, McRorie E, Fraser WD et al. Osteoporosis associated with neutralising autoantibodies to osteoprotegerin. N Eng J Med 2009; 36I:|459-65. doi:I0.1056/NEJMoa08I0925

\section{CONFERENCING AND EVENTS}

The Royal College of Physicians of Edinburgh has a unique blend of rooms providing perfect surroundings for your conference, meeting or event. The Victorian Great Hall, galleried New Library and the Georgian Cullen Suite are wonderful settings for dinners and receptions. The modern Conference Centre seats up to 300 people in raked seating and is complemented by breakout rooms seating from 10 to 150 people, a keypad voting system and video conferencing. The College provides a stunning setting for weddings and receptions and is licensed for both civil and religious ceremonies. Discounts are available for Fellows and Members, medical conferences and charities.

For more information or for a quotation, please contact the Events Team on +44 (0) I 3 I 225 7324; email events@rcpe.ac.uk or visit http://www.rcpe.ac.uk/conferencing/index.php 